\title{
Goal-directed perfusion to reduce acute kidney injury: A randomized trial \\ A randomized trial
}

Marco Ranucci, MD, FESC, ${ }^{\mathrm{a}}$ Ian Johnson, CCP, ${ }^{\mathrm{b}, \mathrm{c}}$ Timothy Willcox, CCP, ${ }^{\mathrm{d}, \mathrm{e}}$ Robert A. Baker, PhD, CCP, Christa Boer, MD, PhD, ${ }^{g, h}$ Andreas Baumann, MD, ${ }^{\mathrm{i}, \mathrm{j}}$ George A. Justison, CCP, ${ }^{\mathrm{k}, \mathrm{l}}$ Filip de Somer, CCP, ${ }^{\mathrm{m}}$ Paul Exton, BSc (Hon) ACP, ${ }^{\mathrm{n}}$ Seema Agarwal, FRCA, ${ }^{\text {b,c }}$ Rachael Parke, PhD, ${ }^{\mathrm{d}, \mathrm{e}}$ Richard F. Newland, CCP, Renard G. Haumann, CCP, ${ }^{\mathrm{g}, \mathrm{h}}$ Dirk Buchwald, PhD, CCP, ${ }^{\mathrm{i}, \mathrm{j}}$ Nathaen Weitzel, MD, ${ }^{\mathrm{k}, \mathrm{l}}$ Rajamiyer Venkateswaran, MD FRCS(Cth), ${ }^{\mathrm{n}}$ Federico Ambrogi, $\mathrm{PhD},{ }^{\circ}$ and Valeria Pistuddi ${ }^{\mathrm{a}}$

\section{ABSTRACT}

Objective: To determine whether a goal-directed perfusion (GDP) strategy aimed at maintaining oxygen delivery $\left(\mathrm{DO}_{2}\right)$ at $\geq 280 \mathrm{~mL} \cdot \mathrm{min}^{-1} \cdot \mathrm{m}^{-2}$ reduces the incidence of acute kidney injury (AKI).

Methods: This multicenter randomized trial enrolled a total of 350 patients undergoing cardiac surgery in 9 institutions. Patients were randomized to receive either GDP or conventional perfusion. A total of 326 patients completed the study and were analyzed. Patients in the treatment arm were treated with a GDP strategy during cardiopulmonary bypass (CPB) aimed to maintain $\mathrm{DO}_{2}$ at $\geq 280 \mathrm{~mL} \cdot \mathrm{min}^{-1} \cdot \mathrm{m}^{-2}$. The perfusion strategy for patients in the control arm was factored on body surface area and temperature. The primary endpoint was the rate of AKI. Secondary endpoints were intensive care unit length of stay, major morbidity, red blood cell transfusions, and operative mortality.

Results: Acute Kidney Injury Network (AKIN) stage 1 was reduced in patients treated with GDP (relative risk [RR], $0.45 ; 95 \%$ confidence interval $[\mathrm{CI}]$, $0.25-0.83 ; P=.01)$. AKIN stage $2-3$ did not differ between the 2 study arms (RR, $1.66 ; 95 \%$ CI, 0.46-6.0; $P=.528$ ). There were no significant differences in secondary outcomes. In a prespecified analysis of patients with a CPB time between 1 and 3 hours, the differences in favor of the treatment arm were more pronounced, with an RR for AKI of 0.49 (95\% CI, 0.27-0.89; $P=.017)$.

Conclusions: A GDP strategy is effective in reducing AKIN stage 1 AKI. Further studies are needed to define perfusion interventions that may reduce more severe levels of renal injury (AKIN stage 2 or 3). (J Thorac Cardiovasc Surg 2018;156:1918-27)

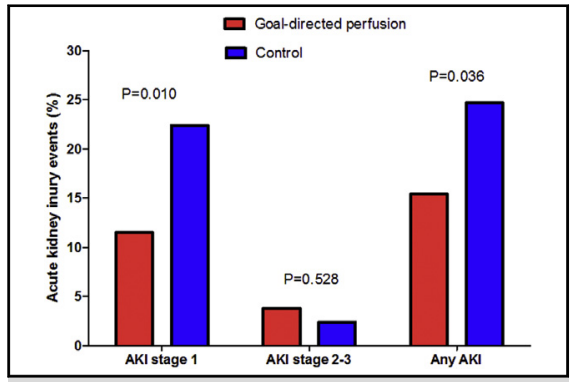

Acute kidney injury in the goal-directed perfusion and control groups.

\section{Central Message}

A goal-directed perfusion strategy aimed at preserving oxygen delivery during cardiopulmonary bypass is effective in reducing AKIN class 1 postoperative acute kidney injury.

\section{Perspective}

Acute kidney injury (AKI) is a major complication of cardiac surgery. This study demonstrates that minor patterns of AKI in medium- to low-risk patients may be limited by a strategy of cardiopulmonary bypass based on a target oxygen delivery. Further studies are needed to define perfusion interventions that may reduce more severe levels of renal injury (AKIN stage 2 or 3 ).

See Editorial Commentary page 1928.
From the a Department of Cardiothoracic and Vascular Anesthesia and Intensive Care Unit, Istituto di Ricovero e Cura a Carattere Scientifico, Policlinico San Donato, San Donato Milanese, Milan, Italy; Departments of ${ }^{\mathrm{b}}$ Perfusion and ${ }^{\mathrm{c}}$ Anesthesia, Liverpool Heart and Chest Hospital, Liverpool, United Kingdom; ${ }^{\mathrm{d}}$ Green Lane Cardiothoracic Unit and Cardiothoracic and Vascular Intensive Care, Auckland

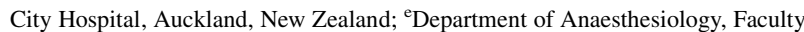
of Medical and Health Sciences, University of Auckland, Auckland, New Zealand; ${ }^{\mathrm{f}}$ Cardiac Research and Perfusion, Cardiac and Thoracic Surgical Unit, Flinders Medical Centre and Flinders University, Adelaide, South Australia; Departments of ${ }^{\mathrm{g}}$ Anesthesiology and ${ }^{\mathrm{h}}$ Cardiothoracic Surgery, Institute for Cardiovascular Research, VU University Medical Center, Amsterdam, The Netherlands; ' Department of Anaesthesiology, Intensive Care, Palliative Care and Pain Medicine and ${ }^{\mathrm{j}}$ Department of Cardiac and Thoracic Surgery, BG University Hospital Bergmannsheil, Ruhr University, Bochum, Germany; Departments of ${ }^{\mathrm{k}}$ Perfusion and ${ }^{\mathrm{l}}$ Anesthesiology, University of Colorado Denver, Aurora, Colo; ${ }^{\mathrm{m}}$ Heart Centre, University Hospital Ghent, Ghent, Belgium; ${ }^{\mathrm{n}}$ Department of Cardiothoracic Surgery, University Hospital of South Manchester National Health Service Foundation Trust, Manchester, United Kingdom; and ${ }^{\circ}$ Department of Clinical Sciences and
Community Health, University of Milan, and IRCCS Policlinico San Donato, Milan, Italy.

The Istituto di Ricovero e Cura a Carattere Scientifico, Policlinico San Donato is a research hospital recognized and partially funded by the Italian Ministry of Health. LivaNova provided external funding for the creation and maintenance of the electronic data platform (Advice Pharma) and for the meetings of the GIFT investigators. LivaNova had no role in the design and performance of the study; the collection, management, analysis, and interpretation of data; the preparation, review, or approval of the manuscript; or the decision to submit the manuscript for publication.

Registered at Clinicaltrials.gov (NCT02250131).

Received for publication Aug 18, 2017; revisions received April 4, 2018; accepted for publication April 7, 2018; available ahead of print May 16, 2018.

Address for reprints: Marco Ranucci, MD, FESC, Department of Anesthesia and Intensive Care, IRCCS Policlinico San Donato, via Morandi 30, 20097 San Donato Milanese, Milan, Italy (E-mail: cardioanestesia@virgilio.it). 0022-5223/\$36.00

Copyright (c) 2018 by The American Association for Thoracic Surgery https://doi.org/10.1016/j.jtcvs.2018.04.045 

Abbreviations and Acronyms
AIC = Akaike information criterion
AKI = acute kidney injury
AKIN = Acute Kidney Injury Network
$\mathrm{ARF}=$ acute renal failure
$\mathrm{CI}=$ confidence interval
$\mathrm{CPB}=$ cardiopulmonary bypass
$\mathrm{DO}_{2}=$ oxygen delivery
GDP = goal-directed perfusion
GIFT $=$ Goal-Directed Perfusion Trial
$\mathrm{HCT}=$ hematocrit
ICU = intensive care unit
$\mathrm{IQR}=$ interquartile range
$\mathrm{OR}=$ odds ratio
$\mathrm{RBC}=$ red blood cell
$\mathrm{RCT}=$ randomized controlled trial
$\mathrm{RR}=$ relative risk
$\mathrm{SvO}_{2}=$ venous oxygen saturation

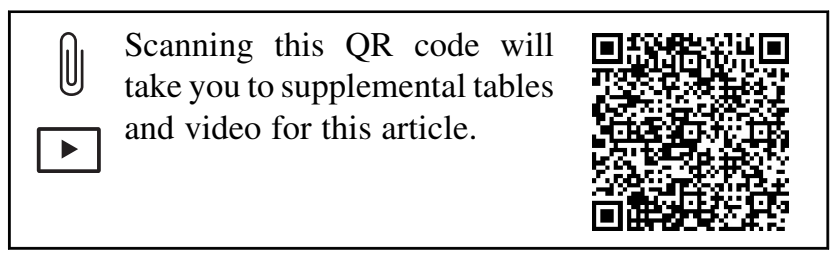

Acute kidney injury (AKI) is a serious complication of cardiac surgery, affecting a considerable proportion of patients and increasing postoperative morbidity and mortality. ${ }^{1}$ Various factors, including age, preoperative renal function, hemodynamic state, and duration and complexity of surgery, have been associated with postoperative AKI. ${ }^{2}$ Studies of AKI following coronary artery bypass graft surgery using the Acute Kidney Injury Network (AKIN) classification have shown that small increases in serum creatinine level (AKIN class 1) increase the risk of end-stage renal disease by 3 -fold (relative risk [RR], 2.92; 95\% confidence interval [CI], 1.87-4.55) and that of mortality by nearly 1.5 -fold (RR, $1.34 ; 95 \% \mathrm{CI}$, $1.23-1.45)^{3}$

An association between the nadir hematocrit (HCT) value during cardiopulmonary bypass (CPB) and postoperative AKI was first reported in $1994 .{ }^{4}$ Numerous retrospective studies subsequently confirmed this finding, and some authors have hypothesized that insufficient oxygen delivery $\left(\mathrm{DO}_{2}\right)$ may be the mechanism underlying the link between severe hemodilution on CPB and poor renal outcomes. ${ }^{5-8}$

Subsequent retrospective studies ${ }^{9-11}$ have confirmed the association between nadir $\mathrm{DO}_{2}$ on $\mathrm{CPB}$ and postoperative AKI, with the identification of a "critical $\mathrm{DO}_{2}$ " in the range of 260 to $272 \mathrm{~mL} \cdot \mathrm{min}^{-1} \cdot \mathrm{m}^{-2}$ for patients undergoing moderately hypothermic $\left(>32^{\circ} \mathrm{C}\right) \mathrm{CPB}$. Based on these observations, the concept of goal-directed perfusion (GDP), aimed at maintaining the $\mathrm{DO}_{2}$ on $\mathrm{CPB}$ above the critical value, was introduced. ${ }^{9}$ The current guidelines of the American Society of Extracorporeal Technology include measurement of $\mathrm{DO}_{2}$ within the standard measurements for assessing arterial pump flow rate. $^{12}$ Historically, the primary strategy for meeting oxygen and metabolic requirements during adult CPB was based on cardiac index, typically in the range of 1.8 to $2.4 \mathrm{~L} \cdot \mathrm{min}^{-1} \cdot \mathrm{m}^{-2}$. However, the concept that arterial pump flow should be adjusted based on the $\mathrm{DO}_{2}$ rather than simply on the basis of the body surface area and temperature is still based on retrospective studies on large patient populations.

To date, high-level evidence demonstrating that a GDP strategy intended to avoid a nadir $\mathrm{DO}_{2}$ below the critical value will reduce the rate of postoperative AKI is lacking. The current study (Goal-Directed Perfusion Trial [GIFT]) sought to test the hypothesis that the GDP approach to avoid a $\mathrm{DO}_{2}$ nadir $<280 \mathrm{~mL} \cdot \min ^{-1} \cdot \mathrm{m}^{-2}$ will reduce the rate of postoperative $\mathrm{AKI}$ in patients undergoing moderately hypothermic $\mathrm{CPB}$.

\section{METHODS \\ Study Design and Population}

The GIFT multicenter randomized controlled trial (RCT) was conducted at 9 institutions in Europe, Australia, New Zealand, and the United States. The study protocol was approved by the Ethics Committee of the coordinating institution (Istituto Di Ricovero e Cura a Carattere Scientifico, Policlinico San Donato; June 17, 2014; protocol 24/int/2014) and by the Ethics Committee or Institutional Review Board of each participating institution before study commencement, and was conducted in accordance with the principles of the Declaration of Helsinki and the International Conference on Harmonisation of Good Clinical Practice guidelines.

Patients were recruited between October 2014 and January 2017. In August 2016, the protocol was amended with minor changes. All patients provided written informed consent to participate before enrolling in the study.

All patients who were age $>18$ years and scheduled for cardiac surgery with an expected CPB duration of $\geq 90$ minutes were eligible for inclusion in the study. Patients were screened at the time of hospital admission or at the first cardiac surgery visit. Specific exclusion criteria were severe chronic renal failure (receipt of dialysis or a serum creatinine level $>3.0 \mathrm{mg} / \mathrm{dL}$ ), emergent surgery; moderate to severe anemia (preoperative HCT $<32 \%$ ), and expected nadir CPB temperature $<32^{\circ} \mathrm{C}$. The values of HCT and serum creatinine considered for inclusion in the study were the last values recorded before surgery. Withdrawal criteria (after randomization) included the need for allogeneic blood transfusions before $\mathrm{CPB}$ (including the use of allogeneic blood to prime the CPB circuit) and an unexpected need for deep hypothermic CPB. Study data were collected prospectively starting on the day before surgery or the day of surgery and extending until hospital discharge (or 30 days after surgery for operative mortality).

\section{Intervention}

Patients were randomized 1:1 into the control arm or the GDP arm. Patients in the GDP arm received a specific intervention aimed to maintain a $\mathrm{DO}_{2}$ value $\geq 280 \mathrm{~mL} \cdot \mathrm{min}^{-1} \cdot \mathrm{m}^{-2}$ during CPB. This intervention was based on adjustment of the arterial pump flow according to the HCT value 
to reach and maintain a $\mathrm{DO}_{2}$ above the prespecified threshold. In the event of low HCT values and an inability to maintain the $\mathrm{DO}_{2}$ above the threshold by increasing the pump flow, 1 unit of red blood cells (RBCs) was transfused if the venous oxygen saturation $\left(\mathrm{SvO}_{2}\right)$ was $<68 \%$ and/or the oxygen extraction rate was $>40 \%$.

The patients in the control arm received arterial pump flow based on body surface area and temperature, with a target value of $2.4 \mathrm{~L} \cdot \mathrm{min}^{-1} \cdot \mathrm{m}^{-2}$ at normothermia. Transfusion of RBCs during $\mathrm{CPB}$ was triggered by the HCT value, according to local institutional standards (Table E1).

With respect to the other perfusion details, the patients were treated according to the local institutional standards. The $\mathrm{DO}_{2}$ levels of patients in both study arms were continuously monitored during $\mathrm{CPB}$, and $\mathrm{SvO}_{2}$ was monitored either continuously or intermittently. Details of the perfusion techniques and equipment are provided in Tables E1 and E2. For patients in the GDP arm, the perfusionist had a direct view of the GDP monitor data to achieve compliance with the GDP protocol. For patients in the control arm, the $\mathrm{DO}_{2}$ value was excluded from the screen of the GDP monitor to avoid any intervention based on $\mathrm{DO}_{2}$ values in the group that was intended to be treated with the conventional strategy.

$\mathrm{DO}_{2}$ data were collected at 20- to 30-second intervals, with the $\mathrm{DO}_{2}$ value during $\mathrm{CPB}$ reported for the study at 10 -minute intervals. For the purpose of this study, the nadir $\mathrm{DO}_{2}$ value was defined as the lowest value maintained for at least 2 consecutive measurements (10-minute intervals) and expressed as the mean of the 2 consecutive measurements. An example of data collection during CPB is provided in Video 1.

\section{Study Outcomes}

The primary outcome of the GIFT was the postoperative rate of AKI. For this study, AKI was defined according to the creatinine changes specified in the AKIN classification. ${ }^{13}$ AKI stage 1 is defined as an increase in serum creatinine level of $150 \%$ to $200 \%$ of baseline or an absolute increase of $\geq 0.3 \mathrm{mg} / \mathrm{dL}$, and AKI stage 2 as an increase in serum creatinine level of $>200 \%$ of the baseline value, within the first 48 hours postsurgery. Patterns of AKI stage 3 are incorporated in the AKI stage 2 definition. Minor serum creatinine changes were defined as "any serum creatinine increase." The primary outcome was therefore defined in terms of AKI stage 1, stage 2-3, any AKI, and any serum creatinine increase.

Secondary outcomes were intensive care unit (ICU) length of stay; major morbidity (ie, mechanical ventilation for $>24$ hours, stroke, deep sternal wound infection, acute renal failure [ARF; defined as renal replacement therapy or a serum creatinine level $>4.0 \mathrm{mg} / \mathrm{dL}$ at any postoperative time point], reoperation, or mortality); rate of receipt of RBC transfusion and number of units transfused; and operative mortality (in-hospital or within 30 days of surgery after discharge). The presence of morbidities was considered for the safety analysis.

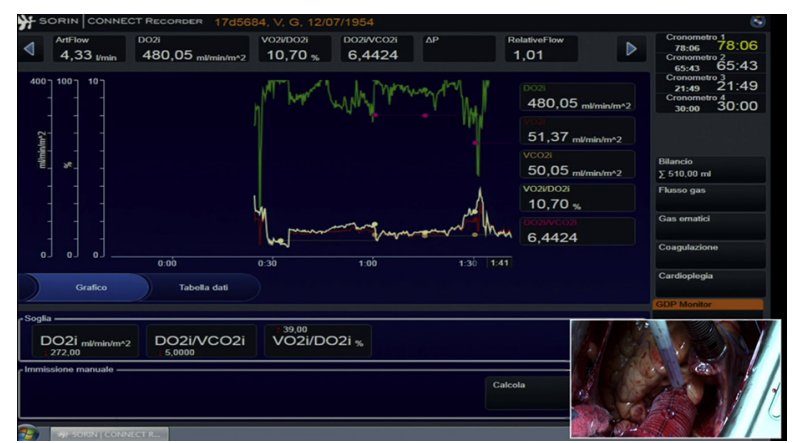

VIDEO 1. Monitoring of goal-directed perfusion with a dedicated tool. Video available at: https://www.jtcvs.org/article/S0022-5223(18)31029-8/ fulltext.

\section{Randomization}

The participants were randomized with a Web-based randomization protocol using a nonstratified fixed-block size of 4 . The order of blocks was also randomized. Randomization was performed on the day of surgery in the majority of the cases. The medical team involved in the surgical process (ie, surgeon, perfusionist, and anesthesiologists) was aware of the patients' treatment arm assignment, but staff members involved in the postoperative care in the ICU and ward were not. The patient files did not contain information related to the study arm, to avoid different treatments in the ICU.

\section{Sample Size Calculation}

Sample size calculation was based on a previous study ${ }^{10}$ retrospectively comparing AKI rates in patients with a nadir $\mathrm{DO}_{2}$ on $\mathrm{CPB}$ of $\geq 280 \mathrm{~mL} \cdot \mathrm{min}^{-1} \cdot \mathrm{m}^{-2}$ or $<280 \mathrm{~mL} \cdot \mathrm{min}^{-1} \cdot \mathrm{m}^{-2}$, by retrieving the original rough dataset. The rate of AKI (stage 1 or 2 ) was $12 \%$ in the former group and $30 \%$ in the latter. Based on these figures, and with a power of $80 \%$ and a significance level of $0.05,2$ groups of 80 patients each were needed to confirm the difference in AKI rates within the RCT. However, based on the experimental design, it was considered that the control arm could include a rate of patients spontaneously reaching and maintaining the critical $\mathrm{DO}_{2}$, and that some patients in the GDP arm might not reach and maintain the desired $\mathrm{DO}_{2}$ value despite our efforts. These rates were prudentially settled at $50 \%$ and $5 \%$, respectively. Based on this assumption, the hypothesized AKI rate would be $21 \%$ in the control arm and $12.8 \%$ in the GDP arm, leading to a sample size of 327 patients per each arm. Considering a plausible rate of patients lost for the final analysis, the sample size was finally settled at 2 groups of 350 patients each.

\section{Statistical Analysis}

Interim analyses were planned at $25 \%, 50 \%$, and $75 \%$ of patient recruitment, with stopping rules for safety, futility, and efficacy (see Online Data Supplement). The protocol was amended in August 2016 following completion of the first interim analysis (data closed in February 2016). The amendments included the inclusion of a subgroup analysis based on bypass time (see below) and a change to the stopping rule for efficacy from $P<.005$ at the $50 \%$ interim analysis to $P<.05$. Data are presented as mean \pm standard deviation for continuous normally distributed variables, median and interquartile range (IQR) for continuous non-normally distributed variables, and number and percentage for categorical variables. The normality of distribution was tested with the Kolmogorov-Smirnov test. Missing data for the primary outcome (baseline and peak serum creatinine levels) were assumed to be missing completely, and these patients were excluded from the efficacy analysis.

The analysis was based on an intention to treat. Differences in the primary and secondary dichotomous outcome measures between the GDP arm and the control arm were tested using an RR analysis, producing an RR with $95 \% \mathrm{CI}$, and the significance level was assessed with the Pearson $\chi^{2}$ or Fisher exact test as appropriate.

Comparisons of continuous non-normally distributed secondary outcome measurements (ICU stay and number of RBC units transfused) were based on nonparametric tests. The Student $t$ test was used for continuous normally distributed variables.

Two (generalized) mixed-effects models were implemented: a regression model for $\mathrm{DO}_{2}$ level over time and a regression model for the probability of $\mathrm{DO}_{2}$ level dropping below $280 \mathrm{~mL} \cdot \mathrm{min}^{-1} \cdot \mathrm{m}^{-2}$ over time. The effect of time was modeled considering restricted cubic splines with 3 or 4 knots. The choice among a simple linear effect and the 2 different spline representations was performed using the Akaike information criterion (AIC). The interaction between time and treatment was used to allow for different patterns of the 2 investigated quantities over time according to treatment. The interaction was tested using likelihood ratio tests. Random intercepts at patient and center levels were considered for 


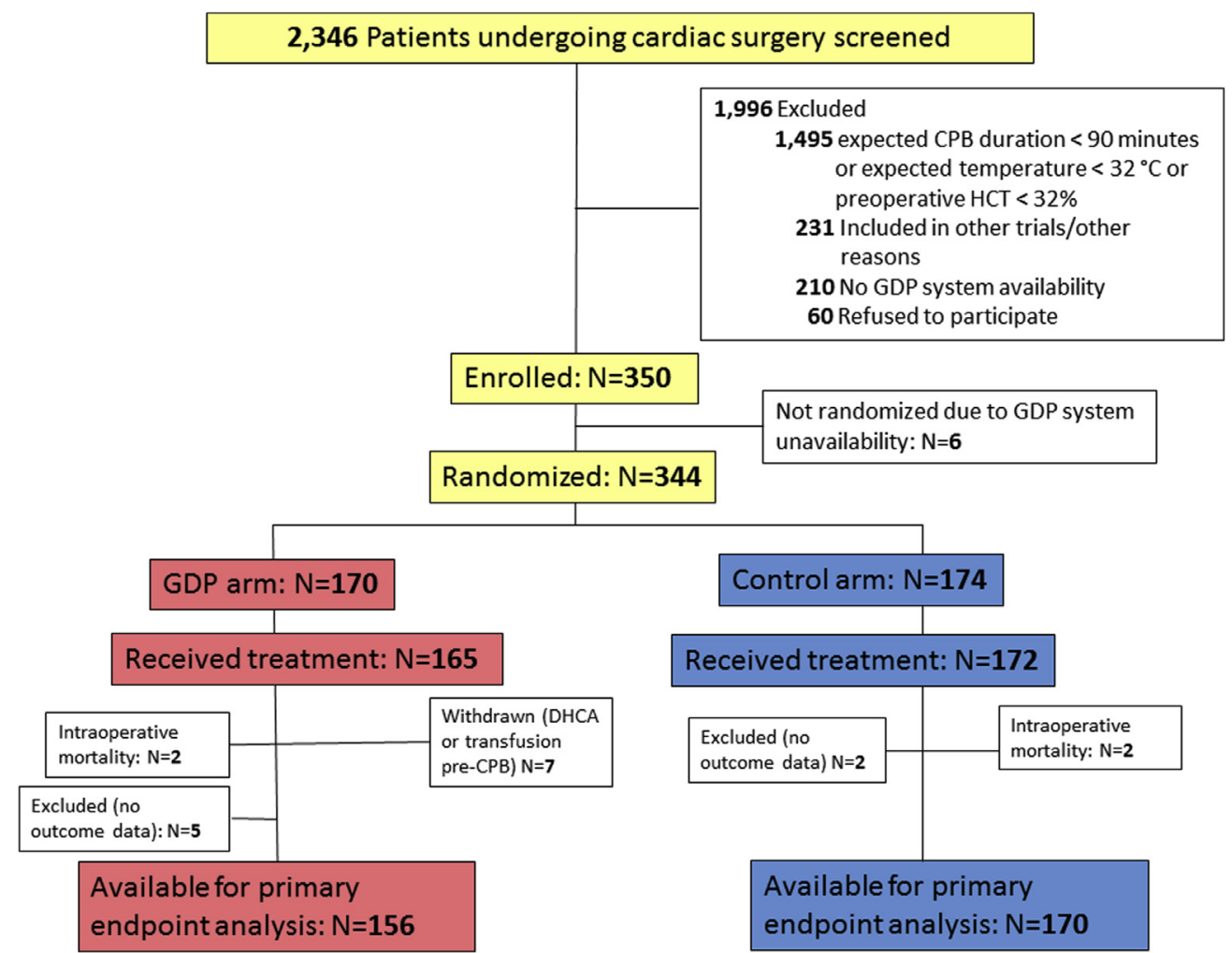

FIGURE 1. Diagram showing the flow of participants through each stage of the trial. $C P B$, Cardiopulmonary bypass; $H C T$, hematocrit; $G D P$, goal-directed perfusion; $D H C A$, deep hypothermic circulatory arrest.

both the generalized linear and linear mixed-effects models. For the linear mixed-effects model, random slopes for time effect were considered as well. Simulation-based $95 \%$ CIs for predicted marginal probabilities of the generalized mixed models were calculated.

A multivariable logistic regression model was applied to the outcome variable AKIN stage 1 to adjust the effect of the experimental variable (GDP) for the potential effects of RBC transfusion, participating institution, and differences in the baseline renal risk, defined according to the acute renal failure (ARF) score. ${ }^{14}$

A prespecified subgroup analysis excluding patients with a short or very long duration of CPB was performed. This subgroup analysis was justified by the fact that the entry criterion was an expected CPB duration $>90$ minutes. To avoid a negligible experimental effect (short exposure to a low nadir $\mathrm{DO}_{2}$ ), the subgroup analysis excluded all patients with a $\mathrm{CPB}$ duration $<1$ hour. At the same time, an excessively long CPB time may lead to difficulty in weaning from CPB (with reduced arterial pump flow during $\mathrm{CPB}$ weaning and reduced postoperative cardiac output), and thus possible postoperative renal dysfunction may be related to these factors rather than to the experimental effect. Therefore, patients with a $\mathrm{CPB}$ duration $>90$ th percentile of the $\mathrm{CPB}$ time distribution were excluded by the subgroup analysis.

The statistical analyses were performed using SPSS 13.0 (SPSS, Chicago, Ill), MedCalc (Ostend, Belgium), or Stata 15.0 (StataCorp, College Station, Tex). A $P$ value $<.05$ was considered to indicate statistical significance.

\section{RESULTS}

The study was halted prematurely after 26 months because the efficacy endpoint at the $50 \%$ interim analysis had been met, according to the stopping rules. During the study period, 2346 patients were screened for participation in the GIFT (Figure 1), of whom 1996 were excluded primarily for failure to meet the inclusion criteria. A total of 350 patients were enrolled but only 344 were randomized, due to an unexpected unavailability of the GDP monitor. An additional 7 patients (5 in the GDP arm and 2 in the control arm) received the allocated treatment but lacked outcome data. The withdrawal criteria were met by 7 patients in the GDP arm but by no patients in the control arm. Finally, 2 patients in each arm died during surgery or immediately after arrival in the ICU, thus missing the peak postoperative serum creatinine measurement. This left 326 patients (GDP arm, $\mathrm{n}=156$; control arm, $\mathrm{n}=170$ ) available for the primary outcome analysis and 330 patients available for the secondary outcome (mortality) analysis.

Table 1 presents patient baseline and intraoperative characteristics. The 2 arms were comparable, with a significantly higher preoperative serum creatinine value in the GDP arm but no difference in baseline creatinine clearance. The median CPB duration was 116 minutes in the GDP arm and 109 minutes in the control arm. Twenty-two patients $(14.1 \%)$ in the GDP arm and 47 $(27.6 \%)$ in the control arm did not reach the expected 
TABLE 1. Demographic data, preoperative profile, and operative details of the patient population

\begin{tabular}{|c|c|c|}
\hline Variable & GDP $\operatorname{arm}(n=156)$ & Control $\operatorname{arm}(n=170)$ \\
\hline Age, y, median (IQR) & $68(59-75)$ & $67(59-74)$ \\
\hline Male sex, n (\%) & $108(69.2)$ & $125(73.5)$ \\
\hline Body surface area, $\mathrm{m}^{2}$, mean (SD) & $2.04(0.24)$ & $2.01(0.24)$ \\
\hline NYHA class, median (IQR) & $2(2-3)$ & $2(2-3)$ \\
\hline Extracardiac arteriopathy, n (\%) & $11(7.1)$ & $15(8.8)$ \\
\hline Poor mobility, n (\%) & $3(1.9)$ & $4(2.4)$ \\
\hline Previous cardiac surgery, n (\%) & $7(4.5)$ & $11(6.5)$ \\
\hline Chronic lung disease, n (\%) & $12(7.7)$ & $13(7.6)$ \\
\hline Previous cerebrovascular accident, $\mathrm{n}(\%)$ & $10(6.4)$ & $9(5.3)$ \\
\hline Active endocarditis, n (\%) & $0(0)$ & $2(1.2)$ \\
\hline Diabetes (insulin-dependent), n (\%) & $13(8.3)$ & $10(5.9)$ \\
\hline Angina class $4, \mathrm{n}(\%)$ & $1(0.6)$ & $2(1.2)$ \\
\hline Recent myocardial infarction, n (\%) & $18(11.5)$ & $10(5.9)$ \\
\hline Pulmonary hypertension, n (\%) & $12(7.7)$ & $18(10.6)$ \\
\hline EuroSCORE II, mean (SD) & $2.6(3.8)$ & $2.5(2.9)$ \\
\hline Hematocrit, \%, median (IQR) & $39(36-42)$ & $39(36-43)$ \\
\hline Left ventricular ejection fraction, $\%$, median (IQR) & $55(50-60)$ & $55(50-60)$ \\
\hline Serum creatinine, $\mathrm{mg} / \mathrm{dL}, *$ mean $(\mathrm{SD})$ & $1.03(0.26)$ & $0.97(0.23)$ \\
\hline Creatinine clearance, $\mathrm{mL} / \mathrm{min}$, median (IQR) & $80(63-103)$ & $82(65-101)$ \\
\hline Acute renal failure score, median (IQR) & $0(1-2)$ & $0(0-1)$ \\
\hline CPB duration, min, median (IQR) & $116(95-144)$ & $109(86-144)$ \\
\hline Aortic cross clamp-time duration, min, median (IQR) & $84(65-108)$ & $82(65-113)$ \\
\hline Lowest temperature on $\mathrm{CPB},{ }^{\circ} \mathrm{C}$, median (IQR) & $33(32-34)$ & $33(32-34)$ \\
\hline Nadir oxygen delivery, $\mathrm{mL} \cdot \mathrm{min}^{-1} \cdot \mathrm{m}^{-2}$, median $(\mathrm{IQR}) \dagger$ & $315(290-350)$ & $301(270-345)$ \\
\hline Delta creatinine, mg/dL, median (IQR) & $-0.04(-0.08$ to 0.19$)$ & $0.07(-0.08$ to 0.30$)$ \\
\hline Priming volume, mL, median (IQR) & $930(800-1262)$ & $930(653-1260)$ \\
\hline \multicolumn{3}{|l|}{ Priming nature, $\mathrm{n}(\%)$} \\
\hline Crystalloids & $86(55.1)$ & $92(54.1)$ \\
\hline Artificial colloids & $38(24.4)$ & $46(27.1)$ \\
\hline Crystalloids and colloids & $18(11.5)$ & $16(9.4)$ \\
\hline $20 \%$ albumin & $14(9.0)$ & $16(9.4)$ \\
\hline \multicolumn{3}{|l|}{ Type of surgery, n (\%) } \\
\hline Isolated coronary surgery & $44(28.2)$ & $42(24.7)$ \\
\hline Other isolated procedure & $40(25.6)$ & $65(38.2)$ \\
\hline Double procedure & $63(40.4)$ & $54(31.8)$ \\
\hline Triple procedure & $9(5.8)$ & $9(5.3)$ \\
\hline Ascending aorta & $20(13.0)$ & $25(14.7)$ \\
\hline
\end{tabular}

$G D P$, Goal-directed perfusion; $I Q R$, interquartile range; $S D$, standard deviation; $N Y H A$, New York Heart Association; $C P B$, cardiopulmonary bypass. Only significant differences: $* P=.036 \dagger P=.013$.

CPB duration of 90 minutes, and 3 patients $(1.9 \%)$ in the GDP arm and $11(6.5 \%)$ in the control arm had a CPB duration of $<1$ hour.

A nadir $\mathrm{DO}_{2}<280 \mathrm{~mL} \cdot \mathrm{min}^{-1} \cdot \mathrm{m}^{-2}$ occurred in 23 of 156 patients $(14.5 \%)$ in the GDP arm and in 52 of $170(30 \%)$ in the control arm (RR, 2.6; 95\% CI, 1.5-4.6; $P<.001)$. The
$\mathrm{DO}_{2}$ values at various time points during $\mathrm{CPB}$ are shown in Figure 2.

A mixed model for $\mathrm{DO}_{2}$ differences as a function of time, study arm, and center effect was applied to investigate the efficacy of GDP implementation in achieving a higher $\mathrm{DO}_{2}$ level. Data analysis was restricted to the first 

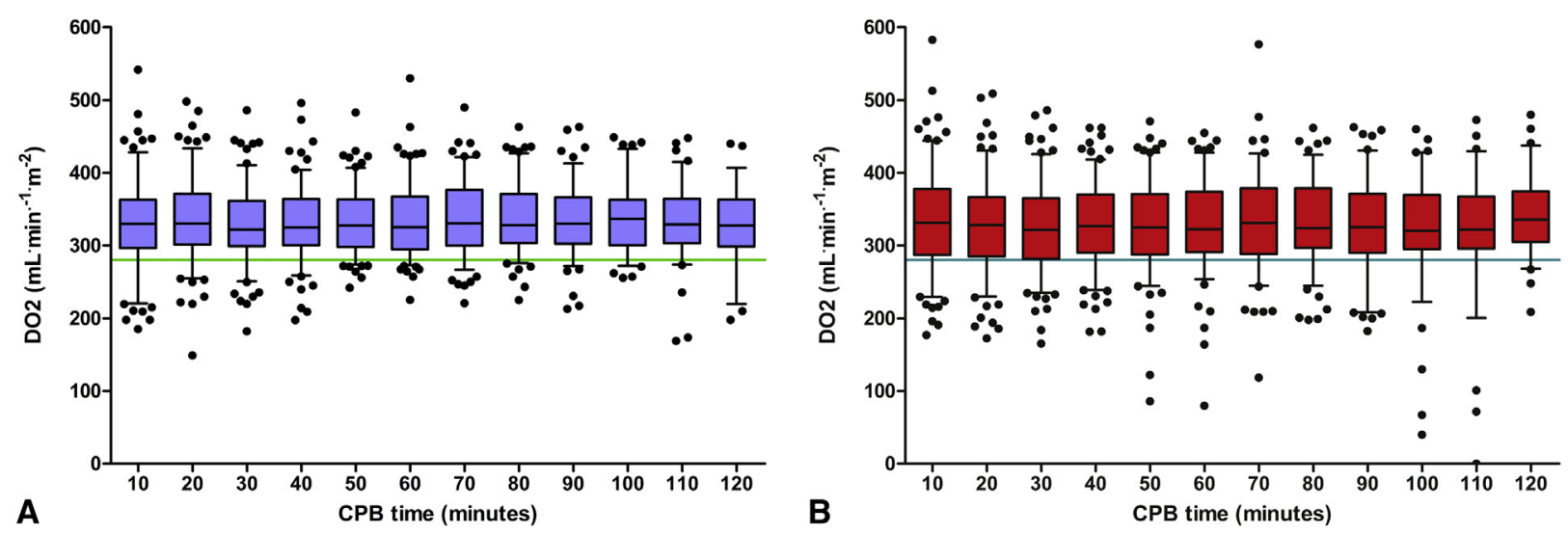

FIGURE 2. Oxygen delivery $\left(\mathrm{DO}_{2}\right)$ values in the goal-directed perfusion (blue; A) and control (red; B) arms during cardiopulmonary bypass $(C P B)$. Boxes represent interquartile range, lines in the boxes represent the median, whiskers are $95 \%$ confidence intervals, and dots are outliers. The green line represents the critical $\mathrm{DO}_{2}$ value of $280 \mathrm{~mL} \cdot \mathrm{min}^{-1} \cdot \mathrm{m}^{-2}$. Data are restricted to the first 120 minutes of CPB.

120 minutes of CPB because of the small sample size after that period (at 40 time points in the GDP arm and 55 in the control arm). The first model considered the absolute $\mathrm{DO}_{2}$ value. Considering the mixed-effects linear regression model for $\mathrm{DO}_{2}$ level as a function of time and treatment, according to the AIC, a restricted cubic spline with 4 knots was used. The model with random slopes for the time effect was always preferred over the model with only random intercepts (independent of the spline representation). The interaction between time and treatment was not significant $(P=.106)$. The estimated marginal levels for patients in GDP group and control are reported in Figure 3. The difference in average $\mathrm{DO}_{2}$ levels between the 2 groups was not significant (difference, $6.82 ; P=.186$ ).

Considering the mixed-effects logit regression model for the probability that $\mathrm{DO}_{2}$ level is $<280 \mathrm{~mL} \cdot \mathrm{min}^{-1} \cdot \mathrm{m}^{-2}$ as a function of time and treatment, according to the AIC, a

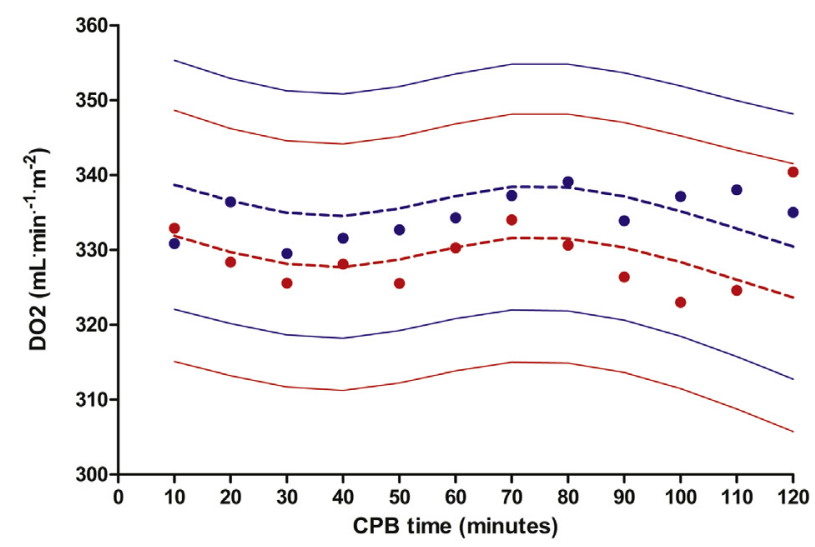

FIGURE 3. Mixed model for oxygen delivery $\left(\mathrm{DO}_{2}\right)$ differences as a function of time, study arm, and center effects. The solid circles represent estimated marginal means, the dotted line is the fitted average, and the solid lines are the $95 \%$ confidence interval (goal-directed perfusion, blue; control, red). The difference in average $\mathrm{DO}_{2}$ levels between the 2 groups was not significant. Data analysis restricted to the first 120 minutes of cardiopulmonary bypass $(C P B)$. restricted cubic spline with 3 knots was used. The interaction between time and treatment was significant $(P=.012,2$ degrees of freedom). The estimated marginal probabilities for patients in the GDP and control arms are reported in Figure 4. The 95\% CIs overlap but do not contain the point estimates. The difference in probability of a $\mathrm{DO}_{2}<280 \mathrm{~mL} \cdot \mathrm{min}^{-1} \cdot \mathrm{m}^{-2}$ between the 2 groups was significant (time 20: odds ratio [OR], 0.36; $P=.023$; time 50: OR, $0.15 ; P=.001$; time 90: OR, $0.17 ; P=.001$ ).

\section{Primary and Secondary Outcomes, Overall Population}

Primary and secondary outcomes are reported in Table 2. AKI stage 1 was found in 18 patients $(11.5 \%)$ in the GDP arm and in 38 patients $(22.4 \%)$ in the control arm (RR,

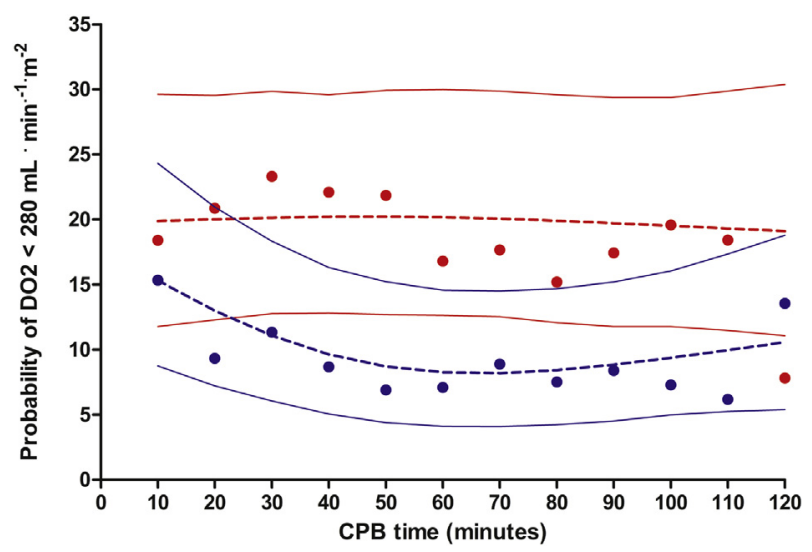

FIGURE 4. Mixed-effects logit regression model for the probability of an oxygen delivery $\left(\mathrm{DO}_{2}\right)$ level $<280 \mathrm{~mL} \cdot \mathrm{min}^{-1} \cdot \mathrm{m}^{-2}$. The solid circles are the observed proportions, the dotted line represents the fitted probabilities, and the solid lines delineate the $95 \%$ confidence interval (goal-directed perfusion, blue; control, red). The goal-directed perfusion group has a significantly lower rate of patients with $\mathrm{DO}_{2}<280 \mathrm{~mL} \cdot \mathrm{min}^{-1} \cdot \mathrm{m}^{-2}$ at 20 $(P=.023), 50(P=.001)$, and $90(P=.001)$ minutes. Data analysis was restricted to the first 120 minutes of cardiopulmonary bypass $(C P B)$. 
TABLE 2. Primary and secondary outcomes, overall population

\begin{tabular}{|c|c|c|c|c|}
\hline Outcome & $\operatorname{GDP} \operatorname{arm}(n=156)$ & Control arm $(n=170)$ & RR or difference $(95 \%$ CI $)$ & $P$ value \\
\hline \multicolumn{5}{|l|}{ Primary outcome } \\
\hline AKI stage 1 & $18(11.5)$ & $38(22.4)$ & $0.45(0.25-0.83)$ & .010 \\
\hline AKI stage $2-3$ & $6(3.8)$ & $4(2.4)$ & $1.66(0.46-6.0)$ & .528 \\
\hline AKI of any kind & $24(15.4)$ & $42(24.7)$ & $0.55(0.32-0.97)$ & .036 \\
\hline Any creatinine increase & $84(53.8)$ & $104(61.2)$ & $0.74(0.48-1.15)$ & .181 \\
\hline \multicolumn{5}{|l|}{ Secondary outcomes } \\
\hline Mortality & $6(3.8)$ & $4(2.3)$ & $1.65(0.46-5.95)$ & .529 \\
\hline Major morbidity & $21(13.3)$ & $25(14.6)$ & $0.89(0.48-1.67)$ & .728 \\
\hline Prolonged MV & $13(8.2)$ & $20(11.8)$ & $0.67(0.2-1.40)$ & .279 \\
\hline Stroke & $2(1.3)$ & $2(1.2)$ & $1.07(0.15-7.7)$ & .942 \\
\hline Renal failure & $2(1.3)$ & $4(2.3)$ & $0.53(0.09-3.0)$ & .686 \\
\hline Reoperation & $5(3.2)$ & $3(1.8)$ & $1.81(0.42-7.7)$ & .490 \\
\hline DSWI & $0(0)$ & $1(0.6)$ & Not applicable & .333 \\
\hline ICU LOS, d, median (IQR) & $2.0(1.0-3.0)$ & $2.0(1.0-3.0)$ & $0.13(-0.94$ to 0.55$)$ & .663 \\
\hline \multicolumn{5}{|l|}{ Transfusion rate } \\
\hline Overall & $55(35)$ & $55(32)$ & $1.15(0.72-1.81)$ & .557 \\
\hline On CPB & $11(7)$ & $6(3.5)$ & $2.1(0.75-5.7)$ & .213 \\
\hline After CPB (operating room) & $10(6.4)$ & $18(10.5)$ & $0.58(0.26-1.29)$ & .235 \\
\hline In the ICU or ward & $43(27.4)$ & $43(25.1)$ & $1.12(0.69-1.84)$ & .645 \\
\hline Number of units, median (IQR) & $0(0-1)$ & $0(0-1)$ & $0.16(-0.61$ to 3.0$)$ & .617 \\
\hline
\end{tabular}

$G D P$, Goal-directed perfusion; $R R$, relative risk; $C I$, confidence interval; $A K I$, acute kidney injury; $M V$, mechanical ventilation; $D S W I$, deep sternal wound infection; $I C U$, intensive care unit; $L O S$, length of stay; $C P B$, cardiopulmonary bypass.

$0.45 ; 95 \%$ CI, $0.25-0.83 ; P=.01)$. AKI stage $2-3$ was found in 6 patients $(3.8 \%)$ in the GDP arm and in 4 patients $(2.4 \%)$ in the control arm (RR, 1.66; $95 \% \mathrm{CI}, 0.46-6.0$; $P=.528)$. AKI stage 1 or stage $2-3$ was found in 24 patients $(15.4 \%)$ in the GDP arm and in 42 patients $(24.7 \%)$ in the control arm (RR, 0.55; 95\% CI, 0.32-0.97; $P=.036$ ). A serum creatinine increase of any level was observed in 84 patients $(53.8 \%)$ in the GDP arm and in 104 patients $(61.2 \%)$ in the control arm (RR, 0.74; 95\% CI, $0.48-1.15 ; P=.181)$.

Because the GDP strategy was based on a $\mathrm{DO}_{2}$-targeted strategy and a specific trigger for RBC transfusions, the effects of nadir $\mathrm{DO}_{2}$ and $\mathrm{RBC}$ transfusion were investigated in a sensitivity analysis. Patients with a nadir $\mathrm{DO}_{2}$ $\geq 280 \mathrm{~mL} \cdot \mathrm{min}^{-1} \cdot \mathrm{m}^{-2}$ had a median serum creatinine increase of $0.04 \mathrm{mg} / \mathrm{dL}$ (IQR, -0.08 to $0.2 \mathrm{mg} / \mathrm{dL}$ ), which was significantly lower $(P=.039)$ than that in patients with a nadir $\mathrm{DO}_{2}<280 \mathrm{~mL} \cdot \mathrm{min}^{-1} \cdot \mathrm{m}^{-2}(0.11 \mathrm{mg} / \mathrm{dL}$; IQR, -0.01 to 0.27 ). They had a significantly lower $(P=.017)$ rate of any kind of serum creatinine increase (55\% vs $71 \%$; OR, $1.99 ; 95 \%$ CI, $1.13-3.51)$, but the AKI stage 1 rate was not significantly different from that of patients with a nadir $\mathrm{DO}_{2}<280 \mathrm{~mL} \cdot \mathrm{min}^{-1} \cdot \mathrm{m}^{-2}(15 \%$ vs $21 \% ; P=.240)$. When tested in a multivariable linear regression model, the absolute increase in serum creatinine levels was not significantly associated with the study arm or the nadir $\mathrm{DO}_{2}$. In a principal component analysis (multivariable logistic regression) for any kind of serum creatinine increase, independent predictors of serum creatinine increase were body surface area, diabetes, recent myocardial infarction, left ventricle ejection fraction, baseline creatinine value, and a nadir $\mathrm{DO}_{2}<280$ $\mathrm{mL} \cdot \min ^{1} \cdot \mathrm{m}^{-2} \quad(\mathrm{OR}, \quad 2.420 ; \quad 95 \% \quad$ CI, $\quad 1.326-4.417$; $P=.004)$ (Table E3).

A multivariable model inclusive of the amount of RBCs transfused during CPB in the operating room (after CPB) and in the ICU and the study arm and adjusted for the center effect and for the preoperative ARF score was applied, with AKI stage 1 as the outcome variable (Table E4). Transfusions of RBC in the ICU was independently associated with AKI stage 1 (OR, 1.31; 95\% CI, 1.10-1.56 per RBC unit). In this model, GDP remained independently associated with a reduction in the AKI stage 1 (OR, 0.48; 95\% CI, 0.25-0.93). No center-based effect was identified.

The median nadir $\mathrm{SvO}_{2}$ on $\mathrm{CPB}$ was $76 \%$ (IQR, $71 \%-81 \%$ ) in the control arm and $77 \%$ (IQR, $72 \%-81 \%)$ in the GDP arm $(P=.391)$. The nadir $\mathrm{SvO}_{2}$ was $76 \%$ (IQR, 72\%-81\%) in patients without AKI stage 1 and $77 \%$ (IQR, $71 \%-81 \%$ ) in patients with AKI stage $1(P=.940)$.

There were no significant differences in secondary outcomes between the 2 arms, and the mortality rate reflected the preoperative risk stratification in both arms.

\section{Primary and Secondary Outcomes, Excluding Short and Long CPB Time}

According to the prespecified subgroup analysis, patients with short ( $<60$ minutes) and long duration of $\mathrm{CPB}$ were excluded. The 90th percentile of CPB time distribution corresponded to 178 minutes, and the exclusion criterion related 
TABLE 3. Primary and secondary outcomes, CPB time 1 to 3 hours

\begin{tabular}{|c|c|c|c|c|}
\hline Outcome & GDP $\operatorname{arm}(n=142)$ & Control arm $(n=144)$ & RR or difference $(95 \%$ CI $)$ & $P$ value \\
\hline \multicolumn{5}{|l|}{ Primary outcome, n (\%) } \\
\hline AKI stage 1 & $16(11.3)$ & $35(24.3)$ & $0.39(0.21-0.75)$ & .004 \\
\hline AKI stage 2-3 & $6(4.2)$ & $4(2.8)$ & $1.54(0.43-5.6)$ & .539 \\
\hline AKI of any kind & $22(15.5)$ & $39(27.1)$ & $0.49(0.27-0.89)$ & .017 \\
\hline Any creatinine increase & $74(52.1)$ & $95(66.0)$ & $0.56(0.35-0.90)$ & .017 \\
\hline \multicolumn{5}{|l|}{ Secondary outcomes } \\
\hline Mortality, n (\%) & $4(2.8)$ & $1(0.7)$ & $4.1(0.45-37)$ & .371 \\
\hline Major morbidity, n (\%) & $16(11.1)$ & 17 (11.9) & $0.93(0.45-1.91)$ & .873 \\
\hline Prolonged MV, n (\%) & $9(6.3)$ & $14(9.8)$ & $0.61(0.26-1.47)$ & .269 \\
\hline Stroke, $\mathrm{n}(\%)$ & $1(0.7)$ & $2(1.4)$ & $0.49(0.04-5.5)$ & .622 \\
\hline Renal failure, $\mathrm{n}(\%)$ & $1(0.7)$ & $3(2.1)$ & $0.33(0.03-3.2)$ & .371 \\
\hline Reoperation, n (\%) & $4(2.8)$ & $3(2.1)$ & $1.33(0.29-6.1)$ & .707 \\
\hline DSWI, n (\%) & $0(0)$ & $1(0.6)$ & Not applicable & .498 \\
\hline ICU LOS, d, median (IQR) & $2.0(1.0-3.0)$ & $2.0(1.0-3.0)$ & $0.13(-0.47$ to 0.74$)$ & .782 \\
\hline \multicolumn{5}{|l|}{ Transfusion rate, $\mathrm{n}(\%)$} \\
\hline Overall & $47(32.9)$ & $47(29.2)$ & $1.19(0.72-1.96)$ & .770 \\
\hline On CPB & $7(4.9)$ & $5(3.5)$ & $2.1(0.75-5.7)$ & .213 \\
\hline After CPB (OR) & $7(4.9)$ & $14(9.8)$ & $0.47(0.18-1.21)$ & .173 \\
\hline In the ICU or ward & $37(25.9)$ & $32(22.4)$ & $1.21(0.70-2.1)$ & .770 \\
\hline Number of units, median (IQR) & $0(0-1)$ & $0(0-1)$ & $0.14(-0.44$ to 0.41$)$ & .948 \\
\hline
\end{tabular}

$G D P$, Goal-directed perfusion; $R R$, relative risk; $C I$, confidence interval; $A K I$, acute kidney injury; $M V$, mechanical ventilation; $D S W I$, deep sternal wound infection; $I C U$, intensive care unit; $L O S$, length of stay; $C P B$, cardiopulmonary bypass; $O R$, operating room.

to excessively long CPB duration was settled at 3 hours, with 142 patients in the GDP arm and 144 in the control arm.

Outcomes in patients with a CPB time between 1 and 3 hours are reported in Table 3. The differences found in the overall population were more pronounced, with an RR for AKI stage 1 of 0.39 (95\% CI, 0.21-0.75; $P=.004)$ and an RR for AKI of any kind of $0.49(95 \% \mathrm{CI}$, $0.27-0.89 ; P=.017$ ). In addition, a serum creatinine increase of any level became significant, with an RR of 0.56 (95\% CI, 0.35-0.90; $P=.017)$.

\section{DISCUSSION}

This study found that use of a GDP strategy aimed at avoiding a $\mathrm{DO}_{2}<280 \mathrm{~mL} \cdot \mathrm{min}^{-1} \cdot \mathrm{m}^{-2}$ on $\mathrm{CPB}$ is effective in reducing the risk of AKIN stage 1 AKI after cardiac surgery. The primary endpoint (avoidance of any AKI as per protocol) was reached at a $P$ value of .036 . These results were more pronounced when patients with a short or very long CPB time were excluded from the analysis. A statistical reduction in the combined endpoint was demonstrated; however, given the low rate of AKI stage 2-3, no meaningful interpretation of that result can be discussed. The main effect refers to AKI stage 1, which is the focus of this discussion.

Our results largely confirm previous retrospective studies, ${ }^{9-11}$ but also provide the first prospective evidence that changing perfusion practice reduces the rate of postoperative AKI. Current perfusion guidelines ${ }^{12}$ advocate limiting hemodilution and consideration of $\mathrm{DO}_{2}$ as a parameter to guide arterial pump flow; no previous RCT has compared patients based on the nadir $\mathrm{DO}_{2}$ or nadir HCT on CPB. A recent study from Magruder and associates $^{15}$ using propensity-score matching compared patients treated with a GDP strategy (aimed at maintaining a $\mathrm{DO}_{2}>300 \mathrm{~mL} \cdot \mathrm{min}^{-1} \cdot \mathrm{m}^{-2}$ ) with a standard perfusion technique. The authors found that patients treated with a GDP strategy had an AKI stage 1 rate of $5.7 \%$, compared with $19.3 \%$ in those not treated with GDP (RR, 0.3). Our results show a lower degree of benefit for the GDP group (RR, 0.45); however, the effect size of the Magruder study is considerably higher, with a mean difference in nadir $\mathrm{DO}_{2}$ reaching $60 \mathrm{~mL} \cdot \mathrm{min}^{-1} \cdot \mathrm{m}^{-2}$.

Cardiac surgery-associated AKI is a serious morbidity, and even minor increases in serum creatinine may lead to permanent damage in renal function. Data from the SWEDEHEART Registry ${ }^{16}$ support the serious impact of small serum creatinine increases by demonstrating both a 3 -fold increase in end-stage kidney disease and increased mortality. Therefore, our finding of a significantly reduced release of serum creatinine (AKIN class 1 AKI) should be considered a strong signal of the efficacy of a GDP strategy leading to a preservation of renal function after cardiac surgery.

Kidney function is highly dependent on oxygen delivery, especially under the conditions of nonpulsatile flow generated by CPB. Owing to its unique blood supply, the kidney medulla enters a hypoxic state under conditions of progressive acute anemia much earlier than the intestine or the heart. ${ }^{17}$ In a recent elegant study, Lannemyr and associates ${ }^{18}$ demonstrated that during $\mathrm{CPB}$, renal $\mathrm{DO}_{2}$ is 
decreased by $20 \%$ due to hemodilution and vasoconstriction, the glomerular filtration rate and renal oxygen consumption remain unchanged, and there is an increase in renal oxygen extraction of up to $45 \%$, indicating a renal oxygen supply/demand mismatch. Therefore, the concept of GDP is sustained by sound physiological and pathophysiological concepts.

Of note, RBC transfusions in the ICU were independently associated with AKI stage 1 . Patients in the GDP arm were less likely to receive RBC transfusions after $\mathrm{CPB}$ and more likely to be transfused during $\mathrm{CPB}$ (although the difference was not statistically significant). This raises the hypothesis that anticipating inevitable RBC transfusions during $\mathrm{CPB}$ may better preserve the $\mathrm{DO}_{2}$ during a critical period, reducing the need for post-CPB transfusion and decreasing the associated AKIN stage 1 risk.

This study has some limitations. Cardiac surgeryassociated AKI is certainly a multifactorial event, and we could not include all of the possible determinants in our analyses. Other factors that could be linked to the incidence of AKI (eg, perfusion pressure, preoperative use of angiotensin-converting enzyme inhibitors, postoperative use of inotropes or vasoconstrictors) were not collected and could not be analyzed. The study was terminated early because the efficacy endpoint was reached at $50 \%$ of the enrollment rate. The efficacy stopping rule change was recommended in August 2016 by the statisticians at the sponsoring institution following the first interim analysis. At that time no safety concerns were raised however the efficacy endpoint was changed in response to the slow recruitment rate. No change in the original $\alpha$ value (0.05) was considered at that time. The original planned sample size of 700 patients was an overestimate, owing to a larger-than-expected effect size and the lack of preliminary data on the rate of patients fulfilling the goal in the GDP and control arms. Trial recruitment was directed at a low-risk patient population, and our rate of AKIN 2-3 highlights that the study was not powered adequately for this outcome. A study focusing on high-risk patients, to gain sufficient power to address major AKI-associated morbidity and mortality, is under consideration.

A second limitation may have been that the majority of the institutions involved in the GIFT were already familiar with the use of GDP monitors and with the concept of GDP. The standard practice in many of the institutions is to limit severe hemodilution, so patients in the control group frequently spontaneously reached the goal of $\mathrm{DO}_{2}$ $\geq 280 \mathrm{~mL} \cdot \mathrm{min}^{-1} \cdot \mathrm{m}^{-2}$. This resulted in a limited, albeit significant, $\mathrm{DO}_{2}$ difference between groups; however, the evidence of a significantly lower rate of patients with $\mathrm{DO}_{2}$ below $280 \mathrm{~mL} \cdot \mathrm{min}^{-1} \cdot \mathrm{m}^{-2}$ in the GDP group demonstrates an acceptable effect size. The problem faced in the present study may be ascribed to a "dilutional" effect. This suggests that future trials should probably include a more carefully prescribed "baseline" protocol, with patients randomized to receive augmented treatment (GDP) over baseline when the target $\left(\mathrm{DO}_{2}\right)$ is not reached.

It would be interesting to assess the efficacy of GDP in centers that accept lower HCT levels on CPB. The $\mathrm{DO}_{2}$ on CPB reflects oxygen supply to all the organs; it would be an interesting subject for future studies to focus on kidney-related markers of $\mathrm{DO}_{2}$ adequacy, including urinary biomarkers or regional oxygen saturation. ${ }^{19}$ In this study design, double-blinding was not possible, and this may be considered an additional limitation. Finally, CPB protocols vary among centers. Tables E1 and E2 list the equipment and protocols for $\mathrm{CPB}$ to help increase the generalizability of our results.

\section{CONCLUSIONS}

A GDP strategy during CPB is effective in reducing the risk of minor patterns of $\mathrm{AKI}$ (any serum creatinine increase and AKIN stage 1) following cardiac surgery in adult patients. However, given the efficacy of GDP in preventing only minor degrees of AKI in low-risk patients, our results do not definitely suggest a change in clinical practice. Further studies are needed to define perfusion interventions that may reduce more severe levels of renal injury (AKIN stage 2 or 3 ).

\section{Conflict of Interest Statement}

Dr Ranucci has developed and patented an algorithm for monitoring $\mathrm{DO}_{2}$ and $\mathrm{VCO}_{2}$ during $\mathrm{CPB}$, which is presently manufactured by LivaNova. Baker and Newland were provided with Vamos Capnographs by LivaNova. Parke received a research grant from Green Lane Research and Education Board for this study. All other authors have nothing to disclose with regard to commercial support.

\section{References}

1. Elmistekawy E, McDonald B, Hudson C, Ruel M, Mesana T, Chan V, et al. Clinical impact of mild acute kidney injury after cardiac surgery. Ann Thorac Surg. 2014;98:815-22.

2. Kristovic D, Horvatic I, Husedzinovic I, Sutlic Z, Rudez I, Baric D, et al. Cardiac surgery-associated acute kidney injury: risk factors analysis and comparison of prediction models. Interact Cardiovasc Thorac Surg. 2015;21:366-73.

3. Rydén L, Sartipy U, Evans M, Holzmann MJ. Acute kidney injury after coronary artery bypass grafting and long-term risk of end-stage renal disease. Circulation. 2014;130:2005-11.

4. Ranucci M, Pavesi M, Mazza E, Bertucci C, Frigiola A, Menicanti L, et al. Risk factors for renal dysfunction after coronary surgery: the role of cardiopulmonary bypass technique. Perfusion. 1994;9:319-26.

5. Fang WC, Helm RE, Krieger KH, Rosengart TK, DuBois WJ, Sason C, et al. Impact of minimum hematocrit during cardiopulmonary bypass on mortality in patients undergoing coronary artery surgery. Circulation. 1997;96(9 Suppl): II-194.

6. Swaminathan M, Phillips-Bute BG, Conlon PJ, Smith PK, Newman MF, Stafford-Smith M. The association of lowest hematocrit during cardiopulmonary bypass with acute renal injury after coronary artery bypass surgery. Ann Thorac Surg. 2003;76:784-91; discussion 792.

7. Habib RH, Zacharias A, Schwann TA, Riordan CJ, Durham SJ, Shah A. Adverse effects of low hematocrit during cardiopulmonary bypass in the adult: should current practice be changed? J Thorac Cardiovasc Surg. 2003;125:1438-50. 
8. Karkouti K, Beattie WS, Wijeysundera DN, Rao V, Chan C, Dattilo KM, et al. Hemodilution during cardiopulmonary bypass is an independent risk factor for acute renal failure in adult cardiac surgery. J Thorac Cardiovasc Surg. 2005; 129:391-400.

9. Ranucci M, Romitti F, Isgrò G, Cotza M, Brozzi S, Boncilli A, et al. Oxygen delivery during cardiopulmonary bypass and acute renal failure after coronary operations. Ann Thorac Surg. 2005;80:2213-20.

10. de Somer F, Mulholland JW, Bryan MR, Aloisio T, Van Nooten GJ, Ranucci M. $\mathrm{O} 2$ delivery and $\mathrm{CO} 2$ production during cardiopulmonary bypass as determinants of acute kidney injury: time for a goal-directed perfusion management? Crit Care. 2011;15:R192.

11. Magruder JT, Dungan SP, Grimm JC, Harness HL, Wierschke C, Castillejo S, et al. Nadir oxygen delivery on bypass and hypotension increase acute kidney injury risk after cardiac operations. Ann Thorac Surg. 2015;100:1697-703.

12. Baker RA, Bronson SL, Dickinson TA, Fitzgerald DC, Likosky DS, Mellas NB, et al. Report from AmSECT's international consortium for evidence-based perfusion: American Society of Extracorporeal Technology Standards and Guidelines for perfusion practice: 2013. J Extra Corpor Technol. 2013;45:156-66.

13. Mehta RL, Kellum JA, Shah SV, Molitoris BA, Ronco C, Warnock DG, et al Acute Kidney Injury Network: report of an initiative to improve outcomes in acute kidney injury. Crit Care. 2007;11:R31.
14. Thakar CV, Arrigain S, Worley S, Yared JP, Paganini EP. A clinical score to predict acute renal failure after cardiac surgery. J Am Soc Nephrol. 2005;16: $162-8$.

15. Magruder JT, Crawford TC, Harness HL, Grimm JC, Suarez-Pierre A, Wierschke C, et al. A pilot goal-directed perfusion initiative is associated with less acute kidney injury after cardiac surgery. J Thorac Cardiovasc Surg. 2017;153:118-25.e1.

16. Liotta M, Olsson D, Sartipy U, Holzmann MJ. Minimal changes in postoperative creatinine values and early and late mortality and cardiovascular events after coronary artery bypass grafting. Am J Cardiol. 2014;113:70-5.

17. van Bommel J, Siegemund M, Henny ChP, Ince C. Heart, kidney, and intestine have different tolerances for anemia. Transl Res. 2008;151:110-7.

18. Lannemyr L, Bragadottir G, Krumbholz V, Redfors B, Sellgren J, Ricksten SE. Effects of cardiopulmonary bypass on renal perfusion, filtration, and oxygenation in patients undergoing cardiac surgery. Anesthesiology. 2017;126:205-13.

19. Choi DK, Kim WJ, Chin JH, Lee EH, Don Hahm K, Yeon Sim J, et al, Intraoperative renal regional oxygen desaturation can be a predictor for acute kidney injury after cardiac surgery. J Cardiothorac Vasc Anesth. 2014;28:564-71.

Key Words: cardiac surgery, cardiopulmonary bypass, oxygen delivery, acute kidney injury

Readers who found these articles interesting may also like to read the following papers found in recent and future issues of our sister publications, Seminars in Thoracic and Cardiovascular Surgery and Operative Techniques in Thoracic and Cardiovascular Surgery!

\section{Adult: Perioperative Management}

ORIGINAL SUBMISSION: Early Outcomes with Rapid- Deployment Versus Stented Biological Valves: A Propensity-Match Analysis. Anthony Nguyen. Semin Thoracic Surg 2018:16-23.

Editorial Commentary: Rapid-Deployment Aortic Valve Replacement: Clear BenefitsWithout a Clear Target Patient Population. Craig M. Jarrett. Semin Thoracic Surg 2018:24-25.

ORIGINAL SUBMISSION: Randomized Trial of Carnitine for the Prevention of Perioperative Atrial Fibrillation. Farzaneh Dastan. Semin Thoracic Surg 2018:7-13.

Editorial Commentary: Preventing Postoperative Atrial Fibrillation: Is There One Best Option? Vincent R. Conti. Semin Thoracic Surg 2018:14-15. 
TABLE E1. Factors affecting calculation of goal-directed perfusion parameters

\begin{tabular}{|c|c|c|c|c|c|c|c|c|}
\hline Site & Oxygenator & $\begin{array}{l}\text { Tubing } \\
\text { coating }\end{array}$ & Flow type & $\begin{array}{l}\text { Blood flow for } \\
\text { GDP calculation }\end{array}$ & $\begin{array}{c}\text { HCT/Hb } \\
\text { measurement } \\
\text { for GDP } \\
\text { calculation }\end{array}$ & GDP calculation* & $\begin{array}{l}\text { Exhaust } \mathrm{CO}_{2} \\
\text { measurement }\end{array}$ & $\begin{array}{c}\text { Patients } \\
\text { enrolled, } \\
\text { n }\end{array}$ \\
\hline 1 & $\mathrm{RX} 25$ & Phisio & Nonpulsatile & US flow distal to all shunts & M4 & CONNECT, $\dagger$ M $4 \ddagger$ & M4/Vamos & 33 \\
\hline 2 & $\begin{array}{l}\text { Inspire6 } \\
\text { Inspire8 }\end{array}$ & Smart & Nonpulsatile & US flow distal to all shunts & M4 & M4 $\ddagger$ & M4 & 54 \\
\hline 3 & Inspire8 & Phisio & Nonpulsatile & Roller pump & CDI 500 & CONNECT $\dagger$ & Vamos & 70 \\
\hline 4 & $\begin{array}{l}\text { Inspire6 } \\
\text { Inspire8 }\end{array}$ & Phisio & Nonpulsatile & US flow distal to all shunts & BCare 5 & CONNECT $\dagger$ & Primus & 69 \\
\hline 5 & Inspire6 & Phisio & Nonpulsatile & Roller pump & SATCRIT & Manually & GE & 13 \\
\hline 6 & $\begin{array}{l}\text { Inspire } 8 \\
\text { Quadrox }\end{array}$ & $\begin{array}{l}\text { Phisio } \\
\text { Softline }\end{array}$ & Nonpulsatile & Roller pump & CDI 500 & CONNECT $\dagger$ & $\begin{array}{l}\text { IntelliVue } \\
\text { G5-M1019A }\end{array}$ & 26 \\
\hline 7 & Inspire 6 & Phisio & Nonpulsatile & US distal to all shunts & BCare 5 & CONNECT $\dagger$ & Ohmeda & 22 \\
\hline 8 & Inspire 8 & Phisio & Nonpulsatile & US flow distal to all shunts & CDI 500 & CONNECT $\dagger^{\dagger}$ & N/A & 33 \\
\hline 9 & Inspire6 & Phisio & Nonpulsatile & Roller pump & Data Master & CONNECT $\dagger$ & Primus & 6 \\
\hline
\end{tabular}

RX25, CDI-500, Terumo Corporation, Tokyo, Japan; Inspire6, Inspire8, Phisio, BCare 5, CONNECT, Data Master, LivaNova, London, United Kingdom; Softline, Maquet, Rastatt, Germany; M4, Spectrum Medical, Gloucester, United Kingdom; Vamos, Primus, Dräger Medical, Lübeck, Germany; SAT/CRIT, Livanova, London, United Kingdom; Ohmeda, General Electric Healthcare, Chicago, Ill; IntelliVue G5-M1019A, Koninklijke Philips, Amsterdam, The Netherlands. GDP, Goal-directed perfusion; HCT, hematocrit; $\mathrm{Hb}$, hemoglobin; $\mathrm{CO}_{2}$, carbon dioxide; $\mathrm{US}$, ultrasound. ${ }^{*} \mathrm{GDP}$ calculated as oxygen content $(\mathrm{mL} / \mathrm{dL}) \times$ pump flow $\left(\mathrm{dL} / \mathrm{min} / \mathrm{m}^{2}\right)$, and oxygen content as hemoglobin $(\mathrm{g} / \mathrm{dL}) \times$ arterial saturation $1.34+0.03 \times \mathrm{PaO}_{2}(\mathrm{mmHg})$. $\dagger$ GDP for CONNECT software: $\mathrm{DO}_{2}=$ Flow $\times\left(\mathrm{Hct} / 2: 94 \times 1: 36 \times \mathrm{SaO}_{2}+\mathrm{PaO}_{2} \times 0.03\right) \times 10$. $\ddagger$ GDP for $\mathrm{M} 4$ : $\mathrm{ecDO}_{2}=10 \times$ Qblood $\times \mathrm{Hb} \times 1.34\left(\mathrm{SaO}_{2} / 100\right)$.

TABLE E2. Perfusion practices

\begin{tabular}{|c|c|c|c|c|c|c|c|c|c|c|}
\hline Site & $\begin{array}{c}\text { Static } \\
\text { prime } \\
\text { volume, } \\
\text { mL }\end{array}$ & Prime nature & $\begin{array}{c}\text { RAP, } \\
\%\end{array}$ & $\begin{array}{c}\text { Hemofiltration, } \\
\%\end{array}$ & $\begin{array}{c}\text { Vacuum- } \\
\text { assisted } \\
\text { venous } \\
\text { return, \% }\end{array}$ & $\begin{array}{c}\text { Blood gas } \\
\text { management }\end{array}$ & $\begin{array}{c}\text { Cell } \\
\text { saver, \% }\end{array}$ & $\begin{array}{c}\text { Transfusion } \\
\text { trigger } \\
\text { (control arm) } \\
\text { on CPB }\end{array}$ & $\begin{array}{c}\text { Target } \\
\text { temperature } \\
\text { on CPB }\end{array}$ & $\begin{array}{c}\text { Target } \\
\text { temperature } \\
\text { for CPB } \\
\text { weaning }\end{array}$ \\
\hline 1 & $1300-1500$ & $\begin{array}{l}20 \% \text { albumin }+ \\
\text { crystalloid }\end{array}$ & 42 & 0 & 0 & Alpha-stat & 64 & $\mathrm{Hb} 7 \mathrm{~g} / \mathrm{dL}$ & $34^{\circ} \mathrm{C} \mathrm{NP}$ & $36^{\circ} \mathrm{C} \mathrm{NP}$ \\
\hline 2 & $1100-1250$ & Crystalloid & 0 & 7 & 0 & Alpha-stat & 21 & $\mathrm{Hb} 7.3 \mathrm{~g} / \mathrm{dL}$ & $32^{\circ} \mathrm{C}-33^{\circ} \mathrm{C} \mathrm{NP}$ & $36^{\circ} \mathrm{C}-37^{\circ} \mathrm{C} \mathrm{NP}$ \\
\hline 3 & 1300 & Crystalloid & 100 & 3 & 31 & Alpha-stat & 0 & $\mathrm{Hb} 7.0 \mathrm{~g} / \mathrm{dL}$ & $32^{\circ} \mathrm{C}-34^{\circ} \mathrm{C}$ NP & $36.5^{\circ} \mathrm{C} \mathrm{NP}$ \\
\hline 4 & 600 & Colloid (gelatins) & 0 & 0 & 100 & Alpha-stat & 45 & $\mathrm{Hb} 7 \mathrm{~g} / \mathrm{dL}$ & $32^{\circ} \mathrm{C} \mathrm{NP}$ & $36^{\circ} \mathrm{C}$ rectal \\
\hline 5 & $800-1200$ & Colloid (gelatins) & 0 & 0 & 0 & Alpha-stat & 100 & $\mathrm{Hb} 7 \mathrm{~g} / \mathrm{dL}$ & $32^{\circ} \mathrm{C} \mathrm{NP}$ & $36^{\circ} \mathrm{C}$ rectal \\
\hline 6 & $900-1300$ & Crystalloid & 0 & 0 & 100 & Alpha-stat & 0 & $\mathrm{Hb} 7.5 \mathrm{~g} / \mathrm{dL}$ & $\begin{array}{l}37^{\circ} \mathrm{C} \mathrm{NP} \text { with } \\
\text { active warming }\end{array}$ & $36^{\circ} \mathrm{C}$ bladder \\
\hline 7 & 935 & Crystalloid & 20 & 100 & 100 & Alpha-stat & 100 & $\mathrm{Hb} 7 \mathrm{~g} / \mathrm{dL}$ & $32^{\circ} \mathrm{C}$ bladder & $36^{\circ} \mathrm{C}$ bladder \\
\hline 8 & 1200 & $\begin{array}{l}\text { Crystalloid + } \\
\text { starches }\end{array}$ & 0 & 0 & 0 & Alpha-stat & 100 & $\mathrm{Hb} 7.3 \mathrm{~g} / \mathrm{dL}$ & $34^{\circ} \mathrm{C}$ rectal & $36^{\circ} \mathrm{C}$ rectal \\
\hline 9 & 605 & Crystalloid & 100 & 0 & 100 & Alpha-stat & 100 & $\mathrm{Hb} 8 \mathrm{~g} / \mathrm{dL}$ & $34^{\circ} \mathrm{C} \mathrm{NP}$ & $36.5^{\circ} \mathrm{C} \mathrm{NP}$ \\
\hline
\end{tabular}

$R A P$, Retrograde autologous prime; $C P B$, cardiopulmonary bypass; $H b$, hemoglobin; $N P$, nasopharyngeal. 
TABLE E3. Component analysis for factors associated with any serum creatinine increase

\begin{tabular}{lccr}
\hline \multicolumn{1}{c}{ Factor } & Regression coefficient & $\boldsymbol{P}$ value & Odds ratio $(\mathbf{9 5} \% \mathbf{C I})$ \\
\hline Body surface area, $\mathrm{m}^{2}$ & 1.479 & .004 & $4.390(1.598-12.062)$ \\
Diabetes & 1.640 & .007 & $5.154(1.578-16.083)$ \\
Recent myocardial infarction & -0.956 & .035 & $0.384(0.158-0.935)$ \\
LVEF $(\%)$ & -0.028 & .013 & $0.972(0.951-0.994)$ \\
Baseline creatinine $(\mathrm{mg} / \mathrm{dL})$ & -1.183 & .023 & $0.306(0.111-0.847)$ \\
$\mathrm{DO}_{2}$ nadir $<280 \mathrm{~mL} \cdot \mathrm{min}^{-1} \cdot \mathrm{m}^{-2}$ & 0.884 & .004 & $2.420(1.326-4.417)$ \\
$\mathrm{Constant}^{-2}$ & -0.182 & & \\
\hline
\end{tabular}

$C I$, Confidence interval; $L V E F$, left ventricular ejection fraction; $\mathrm{DO}_{2}$, oxygen delivery.

TABLE E4. Effects of red blood cell transfusions and study arm in determining acute kidney injury stage 1

\begin{tabular}{lccc}
\multicolumn{1}{c}{ Factor } & Regression coefficient & $\boldsymbol{P}$ value & Odds ratio (95\% CI) \\
\hline RBC units_OR & 0.169 & .685 & $1.184(0.523-2.677)$ \\
RBC units_CPB & -0.490 & .447 & $0.612(0.173-2.167)$ \\
RBC units_ICU & 0.273 & .002 & $1.314(1.103-1.565)$ \\
GDP arm & -0.741 & .029 & $0.477(0.245-0.928)$ \\
Center & N/A & .726 & N/A \\
ARF score & -0.036 & .828 & $0.965(0.700-1.331)$ \\
Constant & -1.697 & & \\
\hline
\end{tabular}

$\overline{C I}$, Confidence interval; $R B C$, red blood cell; $O R$, operating room; $C P B$, cardiopulmonary bypass; $I C U$, intensive care unit; $G D P$, goal-directed perfusion; $N / A$, not applicable; $A R F$, acute renal failure. 